\title{
Trehalase deficiency
}

INSERM

\section{Source}

INSERM. (1999). Orphanet: an online rare disease and orphan drug data base. Trehalase deficiency. ORPHA:103909

This syndrome is characterised by diarrhoea and vomiting after ing estion of trehalose, a disaccharide found mainly in mushrooms. 